\title{
S P E C I A L S E C T I O N G U E S T E D I T O R I A L
}

\section{Quality Control by Artificial Vision}

\author{
Kenneth W. Tobin \\ Oak Ridge National Laboratory \\ Fabrice Meriaudeau \\ Universite De Bourgogne \\ Laboratoire Electronique \\ Informatique et Image \\ 71200 Le Creusot, France
}

Image Science \& Machine Vision

Oak Ridge, Tennessee 37831, USA

\section{Luciano da Fontoura Costa}

Instituto de Fisica de São Carlos

Universidade de São Paulo

São Carlos, Brazil

Artificial vision relates to the application of computers, sensors, methods, and networks to view and interpret the world through the "eyes" of a machine. Research and development in artificial vision has made tremendous strides over the last decade with the availability of high-speed, low-cost computer systems, high-density, high-fidelity vision sensors, and advanced networking capabilities such as those provided by the World Wide Web. Many advances in manufacturing have required tremendous corresponding advances in metrology, inspection, and data interpretation for process characterization and control that rely on the fundamental methods and technologies of artificial vision.

The papers for this special section were solicited from participants of the SPIE 6th International Conference on Quality Control by Artificial Vision held in Gatlinburg, Tennessee, in 2003, as well as from the international community of applied researchers in machine vision. These papers represent innovative concepts and methods for improving the quality and efficiency of industrial processes through artificial vision. This special section presents research and new methods from Austria, France, Germany, and the United States and contains a broad international sampling of applied computer vision research covering image processing, feature analysis, pattern recognition, vision systems, three-dimensional image methods, color and multispectral image analysis, nondestructive testing, and process characterization and control. The papers represent application areas such as agriculture, biomedical, forest products, semiconductors, and metals, in terms of novel theoretical, experimental, and applied work for industrial quality control through improved metrology, inspection, and process characterization.

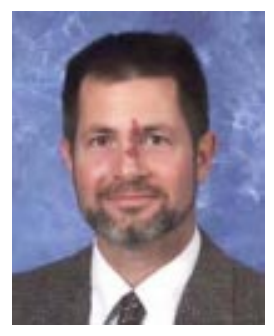

Kenneth W. Tobin is a corporate research fellow and group leader of the Image Science and Machine Vision Group at the Oak Ridge National Laboratory, Oak Ridge, Tennessee. The group performs applied computer vision research and development in industrial inspection, biomedical imaging, and national security. $\mathrm{He}$ performs research in nondestructive testing and analysis, image processing and imagebased metrology, object segmentation, feature generation, and classification from multimodal imagery for process characterization. He has authored or co-authored more than 120 publications and he currently holds six U.S. patents with five additional patents pending in the areas of computer vision, photonics, radiography, and micros- copy. Dr. Tobin is a fellow of SPIE-The International Society for Optical Engineering where he is currently founder and chairman of the conference on Data Analysis and Modeling for Process Control, part of SPIE's Microlithography Symposium. Dr. Tobin is also a member of the Institute of Electrical and Electronics Engineers (IEEE) where he was the first invited U.S. organizer of the 6th International Conference on Quality Control by Artificial Vision held in 2003. He has a $\mathrm{PhD}$ in nuclear engineering from the University of Virginia, Charlottesville, Virginia, and an MS in nuclear engineering and a BS in physics from Virginia Tech., Blacksburg, Virginia.

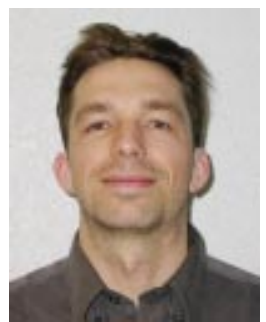

Fabrice Meriaudeau received an engineering degree in material science, a master's degree in physics in 1994, and a PhD in image processing in 1997, from the University of Burgundy. From June 1997 to September 1998, he was a postdoctoral fellow at the Oak Ridge $\mathrm{Na}$ tional Laboratory working in the field of optical sensing and near-field optics. He is an associate professor and the head of the research group (le2i laboratory, UMR CNRS 5158) at the Technical Institute of Le Creusot, University of Burgundy, and his research interests include image segmentation, pattern recognition, and multispectral and infrared imaging. He has authored or co-authored more than 90 papers on optical 


$\begin{array}{lllllllllllllllllllllllllllll}S & P & E & C & \text { I } & A & L & S & E & C & T & \text { I } & O & N & G & U & E & S & T & E & D & \text { I } & T & O & R & \text { I } & A & L\end{array}$

sensing and image processing. He serves as a chairman for various conferences dedicated to machine vision.

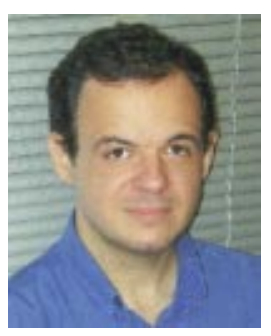

Luciano da Fontoura Costa: received a BSc in electronic engineering from the University of São Paulo at São Carlos, Brazil, an MSc in applied physics from the Institute of Physics (IFSC),

University of São Paulo, and a PhD degree in electronic engineering from King's College, University of London. $\mathrm{He}$ is an associate professor at the IFSC, where he founded the Cybernetic Vision Research Group in 1993. He is the coordinator of the Bioinformatics Graduate Program of the University of São Paulo, and participates in a Human Frontier Project with the Salk Institute and University of Vienna. He is a member of the editorial board of several international journals, and has organized several conferences and special issues. His interests include shape analysis, computer vision, bioinformatics, signal processing, pattern recognition and data mining, neuroinformatics, and visual inspection. 